\title{
Pocket depth and bleeding on probing and their associations with dental, lifestyle, socioeconomic and blood variables: a cross-sectional, multicenter feasibility study of the German National Cohort
}

Heiko Zimmermann ${ }^{1 *+}$, Daniel Hagenfeld ${ }^{2,3+}$, Katja Diercke ${ }^{4}$, Nihad El-Sayed ${ }^{2}$, Julia Fricke ${ }^{5,6}$, Karin Halina Greiser ${ }^{5}$, Jan Kühnisch ${ }^{7}$, Jakob Linseisen ${ }^{8}$, Christa Meisinger ${ }^{8}$, Nicole Pischon ${ }^{9}$, Tobias Pischon ${ }^{10}$, Stefanie Samietz ${ }^{11}$, Marc Schmitter ${ }^{12}$, Astrid Steinbrecher ${ }^{10}$, Ti-Sun Kim² and Heiko Becher ${ }^{1,13}$

\begin{abstract}
Background: To investigate the periodontal disease status in a multi-center cross-sectional study in Germany. Associations of dental, socio-economic, blood and biomedical variables with periodontal outcome parameters were evaluated.

Methods: From 4 different centers $N=311$ persons were included, drawn randomly from the registration offices. Maximal pocket depth (PD) was used as primary indicator for periodontitis. It was classified as: no/mild $\leq 3 \mathrm{~mm}$, moderate 4-5 mm, severe $\geq 6 \mathrm{~mm}$. Associations between socioeconomic (household income, education), lifestyle, and biomedical factors and PD or bleeding on probing (BOP) per site ("Yes"/"No") was analyzed with logistic regression analysis.
\end{abstract}

Results: Mean age of subjects was 46.4 (range 20-77) years. A significantly higher risk of deeper pockets for smokers ( $O R=2.4$, current vs. never smoker) or persons with higher $\mathrm{BMI}(\mathrm{OR}=1.6, \mathrm{BMI}$ increase by 5) was found. Severity of periodontitis was significantly associated with caries lesions $(p=0.01)$, bridges $(p<.0001)$, crowns $(p<.0001)$, leukocytes $(p=0.04)$, HbA1c $(p<.0001)$ and MCV $(p=0.04)$. PD was positively correlated with BOP. No significant associations with BOP were found in regression analysis.

Conclusions: Earlier findings for BMI and smoking with severity of PD were confirmed. Dental variables might be influenced by potential confounding factors e.g. dental hygiene. For blood parameters interactions with unknown systemic diseases may exist.

Keywords: Periodontitis, Dental examination, BMI, Laboratory parameters, Bleeding on probing, German National Cohort

\section{Background}

Periodontitis is a chronic infectious disease which results in biofilm formation on tooth and root surfaces and subsequent destruction of periodontal tissue because of an accelerated host response to pathogenic bacteria. Periodontitis is mostly promoted by microorganisms

\footnotetext{
* Correspondence: h.zimmermann@uni-heidelberg.de

${ }^{\dagger}$ Equal contributors

${ }^{1}$ Institute of Public Health, University of Heidelberg, Im Neuenheimer Feld 324, 69120 Heidelberg, Germany

Full list of author information is available at the end of the article
}

which are the primary cause for developing periodontitis $[1,2]$. Severity and progression of periodontitis is linked to the microbiological burden, the susceptibility of the host and modified by environmental and behavioral factors [3]. Earlier studies found smoking [4,5], diabetes mellitus [6-8] or other risk indicators, e.g. genetic predisposition [9-11], age [12,13], sex [14,15], social and psychological factors [15-17] to be correlated with periodontitis. There is evidence that periodontitis is a risk factor for other diseases. It might lead to higher risk for ischemic $[18,19]$ and hemorrhagic stroke [20],

\section{Ciomed Central}

(c) 2015 Zimmermann et al.; licensee BioMed Central. This is an Open Access article distributed under the terms of the Creative Commons Attribution License (http://creativecommons.org/licenses/by/4.0), which permits unrestricted use, distribution, and reproduction in any medium, provided the original work is properly credited. The Creative Commons Public Domain Dedication waiver (http://creativecommons.org/publicdomain/zero/1.0/) applies to the data made available in this article, unless otherwise stated. 
cardiovascular disease [21,22], myocardial infarction [23,24] and systemic diseases [25,26].

Several studies have shown that periodontitis is highly prevalent in both developing and industrialized countries [27-30]. Recent research has also shown, that periodontitis is highly prevalent in Germany, especially in older ages [31]. In about $10 \%$ of periodontitis cases treatment is necessary even in young patients [32]. Due to the decrease in caries prevalence and the increased amount of maintained teeth periodontal infections are rising and are expected to even increase in future [31].

The prevalence of severe periodontitis $(\geq 6 \mathrm{~mm})$ in adult populations is $5-20 \%$ worldwide [30]. However, disease progression varies regarding different demographic characteristics including age, sex and behavioral factors like smoking [33]. To assess the burden of periodontitis [30] in Germany some surveys have been performed $[34,31,35]$. In Germany, $18 \%$ of individuals show a diagnosis of severe periodontitis in all age groups jointly [36].

The forthcoming German National Cohort (GNC) Study aims at recruiting a representative sample from the general population in Germany [37]. Recruitment will take place in 18 study centers distributed throughout Germany and will include 200.000 people aged between 20 and 69 years. The study aim is to investigate the development of major chronic diseases, subclinical disease stages and functional changes, and to identify strategies for prevention, prediction, and early detection of diseases.

Feasibility studies were conducted in all centers in 2012 to test specific aspects of the GNC. One of these aspects was related to oral health and to test the reliability of the clinical measurements performed by a study nurse compared to the measurement of a dentist and to test the required time for the assessment of the oral variables. Data on periodontal status of study participants in different regions and a wide range of lifestyle and health related variables were collected.

Based on these data we present in this paper results on pocket depth and bleeding on probing status as outcome parameters for periodontal disease and to quantify factors which are associated with these conditions.

\section{Methods}

\section{Study population}

Subjects participated in the pretest phase of a populationbased interdisciplinary epidemiologic cohort study called "The German National Cohort" (GNC) [37,38]. For more information see also http://www.nationale-kohorte.de/. Several feasibility studies have been performed in 2012 to test certain aspects of the main study. This study was performed in four of the 18 participating centers, Heidelberg (south-west Germany), Augsburg (south), Berlin and Greifswald (north-east Germany). These centers were selected because of their specific expertise to perform this particular study.

From the local registration offices random population samples were drawn. However, the feasibility studies were not designed to determine response rates, but to establish processes and to test methods for the final German National cohort in case of the basic program and the additional oral examinations. Some individual data on recruitment processes and response rates for each of the four centers are presented in the Table 1. Between the centers recruitment process (and numbers) varied.

The joint overall sample finally incorporated $n=311$ Germans (120 males, 191 females). The study approval was approved by the following ethics committees; (Charité - Universitätsmedizin Berlin (EA1/101/11), Medizinische Fakultät der Universität Heidelberg (S-108/ 2011), Medizinische Fakultät der Universität Greifswald (BB 12/11), Bayerische Landesärztekammer, München). All participants gave written informed consent. Individuals

Table 1 Recruitment characteristics of the study population for the four centers

\begin{tabular}{|c|c|c|c|c|c|c|c|}
\hline Study center & $\begin{array}{l}\text { Overall } \\
\text { sample }\end{array}$ & Contacted & $\begin{array}{l}\text { Subjects } \\
\text { participated }\end{array}$ & $\begin{array}{l}\text { Overall response } \\
\text { P13 program }\end{array}$ & Drop-outs* & $\begin{array}{l}\text { Recruitment: Additional } \\
\text { approach }\end{array}$ & $\begin{array}{l}\text { Persons for } \\
\text { paper analysis }\end{array}$ \\
\hline Augsburg & $N=920$ & $N=750$ for $\mathrm{P} 13$ & $\mathrm{ROS}^{* *}: \mathrm{N}=228$ & $24.8 \%(228 / 920)$ & $N=522$ & & $N=44$ \\
\hline $\begin{array}{l}\text { Greifswald } \\
\text { (Neu-Brandenburg) }\end{array}$ & $N=291$ & $N=291$ for $\mathrm{P} 13$ & ROS: $N=148$ & $50.9 \%(148 / 291)$ & $N=143$ & $\begin{array}{l}\text { a.) Phone calls ( } 30 \%) \text {, } \\
\text { b.) House visits and media } \\
\text { campains } 70 \%\end{array}$ & $N=107$ \\
\hline \multirow[t]{2}{*}{ Berlin } & \multirow[t]{2}{*}{$N=1667$} & \multirow{2}{*}{$\begin{array}{l}\mathrm{N}=16671 .(\mathrm{N}=967 \\
\text { for } \mathrm{P} 13,2 . \mathrm{N}=700, \\
\text { Basic program only) }\end{array}$} & \multirow{2}{*}{$\begin{array}{l}\text { ROS: } N=13 \\
\text { CS }^{* * *}: N=63\end{array}$} & \multirow[t]{2}{*}{$7.9 \%(76 / 967)$} & \multirow[t]{2}{*}{$N=891$} & a.) ROS & \multirow[t]{2}{*}{$N=70$} \\
\hline & & & & & & b.) $\mathrm{CS}$ & \\
\hline \multirow[t]{2}{*}{ Heidelberg } & \multirow[t]{2}{*}{$N=600$} & \multirow[t]{2}{*}{600} & \multirow[t]{2}{*}{$\begin{array}{l}\text { ROS: } N=143 \text { of } \\
600(23.83 \%)\end{array}$} & \multirow[t]{2}{*}{$16 \%(96 / 600)$} & \multirow[t]{2}{*}{$N=75$} & $\begin{array}{l}\text { a.) Phone calls } 40.3 \% \\
(242 / 600)\end{array}$ & \multirow[t]{2}{*}{$N=90$} \\
\hline & & & & & & $\begin{array}{l}\text { b.) Contacted without } \\
\text { phone number }(358 / 600)\end{array}$ & \\
\hline
\end{tabular}


were invited by letter, with a written reminder and, if required, additional contacts by phone. Each person was interviewed and underwent a full program of medical examinations which includes a blood sample and the oral examination reported in this paper. The total examination time for each person was about 2.5 hours. The dental examinations and dental questionnaires lasted 25 minutes on average.

\section{Dental examination}

The periodontal examination was conducted by study nurses supported by experienced dentists. Study nurses received a two week intensive training and calibration for these examinations. 250 individuals were examined both by study nurses and dentists. The agreement between both was good: $~ 95 \%$ agreement regarding pocket probing depths between study nurses and dentists on examined sites $(\mathrm{N}=6125$ out of 6394$)$ within an error range of $+-2 \mathrm{~mm}$ was present.

Pocket depth (PD) was used as main indicator for the presence of periodontal inflammation. A full-mouth registration for periodontal status was conducted in Heidelberg and a half-mouth registration was carried out in all other study centers. PD was measured on at least two sites per tooth (mesial and mediobuccal) on maxillary and mandible part. For the examination a UNC-PCP15 Color-Coded Probe (Hu-Friedy Europe, Rotterdam/Netherlands) with a black band for each millimeter up to 15 millimeter was used. According to the Community Periodontal Index for Treatment Needs (CPITN) [39] for PD the following definition for periodontitis was used: PD $0-3 \mathrm{~mm}$ as no/mild periodontitis, at least one pocket $\geq 4 \mathrm{~mm}$ and $<6 \mathrm{~mm}$ as moderate and with at least one pocket $\geq 6 \mathrm{~mm}$ as severe periodontitis.

Bleeding on probing (BOP) was measured according to Lang et al. [40] in all study centers except Greifswald. After measuring the PD, the corresponding sites (buccal and mediobuccal) were inspected for the presence or absence of bleeding and noted in an evaluation chart. The absence of BOP can serve as a predictor of periodontal stability [40]. If the percentage of sites with BOP for each person was less than $30 \%$ of all probed sites, it was defined as local bleeding only. A percentage of $30 \%$ of sites or higher was considered as general BOP [41].

Additional dental status parameters (crowns, implants, dentures, missing teeth, caries and bridges) were recorded for full mouth in all centers, except Berlin, where half mouth assessment was performed. In case of these dental parameters data for Berlin were adjusted to full mouth to allow comparisons with the other centers. Caries was assessed as defined by the International Caries Detection and Assessment System (ICDAS) Code 3 as established decay [42]. Mean numbers were calculated for each dental parameter.

\section{Anthropometric and socio-economic variables}

Age was grouped as 20 to $\leq 29,30$ to $\leq 39,40$ to $\leq 49,50$ to $\leq 59$ and $\geq 60$ years. Body mass index was calculated according to measured values and classified in three different groups $<25,25$ to $<30$ and $\geq 30$. Household income was categorized in two groups: $<2000 € /$ month and $\geq 2000 € /$ month. School education was grouped in two levels. Persons with 13 years of school education (A-Level) and those persons having less than 13 years.

\section{Lifestyle factors}

Alcohol consumption was assessed as frequency of consuming alcoholic drinks and grouped as $<2$ times/week or never and $\geq 2$ times/week. Smoking was defined as never smokers, ex-smokers and current smokers. Various terms on physical activity (PA) based on "vigorous", "moderate" and "routes walked" activities were combined and recalculated as metabolic equivalent of task (MET) minutes/week based on the guidelines of the International Physical Activity Questionnaire (IPAQShort) http://www.ipaq.ki.se/scoring.pdf grouped into two groups $(<1500, \geq 1500)$.

\section{Blood parameters and pre-existing diseases}

Blood parameters were measured with following units: Leukocytes as $1 / \mathrm{nl}$, erythrocytes as $1 / \mathrm{pl}$, mean corpuscular/ cell volume $(\mathrm{MCV})$ in $\mathrm{fl}$ and $\mathrm{HbA1c}$ in $\mathrm{mmol} / \mathrm{mol}$. Selfreported diabetes was used as a dichotomous variable ("Yes"/"No").

\section{Statistical methods}

Data are described descriptively, graphically and by appropriate tables. Univariate associations between lifestyle variables, blood parameters and dental status parameters with PD and BOP were assessed with Kruskal-WallisTests, respectively. To assess joint effects of lifestyle and socioeconomic variables on PD and BOP we used ordinal logistic regression, and binary logistic regression, adjusted for age, sex and center by stratification. Statistical calculations were performed using PROC LOGISTIC in SAS version 9.3 (SAS Institute, Cary, North Carolina).

\section{Results}

The mean age of the participants in this study population was 46.4 years and ranged from 20 years to 77 years. More females (61.4\%) than males $(38.6 \%)$ attended. The sex and age distribution by center is given in Table 2 .

Table 3 shows the distribution of the maximum PD and the percentage of sites with bleeding on probing (BOP) by study center. Overall, about half of the study population showed no increased PD or only mild form of periodontitis $(165 / 311,53.1 \%)$. The percentage of sites with BOP was $12.4 \%$ overall. Individual percentages 
Table 2 Demographic characteristics of the study population by center and sex: Number (\%) by center, mean age (standard deviation) and age range

\begin{tabular}{|c|c|c|c|c|c|c|}
\hline & & Augsburg & Berlin & Greifswald & Heidelberg & Total \\
\hline \multirow[t]{3}{*}{ Male } & N (\%) & $19(43.2)$ & $22(31.4)$ & 37 (34.6) & $42(46.7)$ & 120 (38.6) \\
\hline & $\bar{x}(s . d)$. & $56.8(10.8)$ & 41.4 (13.9) & $51.3(13.7)$ & $43.1(15.4)$ & 47.5 (14.9) \\
\hline & Range & $(35-70)$ & $(20-67)$ & $(28-77)$ & $(21-69)$ & $(20-77)$ \\
\hline \multirow[t]{3}{*}{ Female } & N (\%) & $25(56.8)$ & $48(68.6)$ & $70(65.4)$ & $48(53.3)$ & 191 (61.4) \\
\hline & $\bar{x}(s . d)$. & 53.7 (11.9) & $41.0(14.5)$ & $48.3(13.7)$ & $42.6(14.7)$ & $45.7(14.5)$ \\
\hline & Range & (28-69) & $(21-68)$ & $(21-76)$ & $(21-69)$ & $(21-76)$ \\
\hline \multirow[t]{3}{*}{ Total } & N (\%) & $44(14.2)$ & $70(22.5)$ & 107 (34.4) & $90(28.9)$ & $311(100.0)$ \\
\hline & $\bar{x}(s . d)$. & $55.0(11.4)$ & $41.1(14.2)$ & $49.3(13.7)$ & $42.8(15.0)$ & $46.4(14.7)$ \\
\hline & Range & (28-70) & $(20-68)$ & $(21-77)$ & $(21-69)$ & $(20-77)$ \\
\hline
\end{tabular}

varied from $0.0 \%$ to $82 \%$, and were strongly correlated with maximum PD. In contrast to the sites of BOP the distribution of PD differed significantly between study centers $(\mathrm{p}=0.35$ and $\mathrm{p}=0.001)$. This can partly be explained by differences in age distribution.

In Table 4 the distribution of (i) other dental variables (ii) anthropometric, social and lifestyle factors and (iii) blood parameters by PD level and general BOP status is given. Relations of these variables tend to be stronger with PD level than with BOP values. Individuals with high $\mathrm{PD}$ levels had a significantly larger number of teeth with caries, bridges and crowns as individuals with low PD level. Individuals with BOP had a significantly larger number of teeth with crowns than individuals without BOP.

Significantly higher PD levels were also found with increasing body mass index, smoking, lower years of school education and age.

Regarding the blood parameters drawn from blood samples we observed increased values for leukocytes, HbA1c and MCV with increasing PD. No significant associations with BOP were found.
In the multivariable ordinal regression model, adjusted for age, sex and center, BMI and smoking remained significantly associated with PD (see Table 5). Higher BMI (increase by $5, \mathrm{OR}=1.66,95 \% \mathrm{CI}=1.25-2.21$ ), and current smoking $(\mathrm{OR}=2.44,95 \% \mathrm{CI}=1.24-4.80)$ yield a more severe periodontitis.

The logistic regression model for BOP was adjusted for age, sex and center and limited to 209 people. There were no statistically significant associations between the dependent variable BOP and the independent variables.

The two variables PD and BOP were correlated. Figure 1 shows a scatter plot of the individual percentages of sites with $\mathrm{BOP}$ against the maximum PD. Mean BOP values were calculated for each value of PD and included in the figure, indicating the correlation between both variables.

\section{Discussion}

This study provides the first data on periodontal parameters in the framework of the planned GNC in Germany and highlights the need for a thorough assessment of oral health conditions in Germany. The prevalence of

Table 3 Overview on pocket depth (PD) and bleeding on probing (BOP): Number of people on PD by center, mean in percent of BOP sites, range of BOP sites (percent) by center and PD

\begin{tabular}{|c|c|c|c|c|c|c|c|c|c|c|}
\hline & \multicolumn{2}{|c|}{ Augsburg } & \multicolumn{2}{|c|}{ Berlin } & \multicolumn{2}{|c|}{ Greifswald } & \multicolumn{2}{|c|}{ Heidelberg } & \multicolumn{2}{|c|}{ Total } \\
\hline & $\mathrm{N}$ & $\begin{array}{l}\text { Mean BOP sites in } \\
\%), \text { Min-Max in \% }\end{array}$ & $\mathrm{N}$ & $\begin{array}{l}\text { Mean BOP sites in } \\
\%), \text { Min-Max in \% }\end{array}$ & $\mathrm{N}$ & $\begin{array}{l}\text { Mean BOP sites in } \\
\%), \text { Min-Max in \% }\end{array}$ & $\mathrm{N}$ & $\begin{array}{l}\text { Mean BOP sites in } \\
\%), \text { Min-Max in \% }\end{array}$ & $\mathrm{N}$ & $\begin{array}{l}\text { Mean BOP sites in } \\
\%) \text {, Min-Max in \% }\end{array}$ \\
\hline \multicolumn{11}{|c|}{ PD Level } \\
\hline \multirow[t]{2}{*}{$<4 \mathrm{~mm}$} & 15 & 3.5 & 44 & 10.0 & 62 & $N A^{*}$ & 44 & 4.4 & 165 & 6.7 \\
\hline & & $0.0-15.0$ & & $0.0-46.4$ & & & & $0.0-25.0$ & & $0.0-46.4$ \\
\hline \multirow[t]{2}{*}{$4+5 \mathrm{~mm}$} & 16 & 9.9 & 21 & 22.1 & 38 & NA & 26 & 15.0 & 101 & 16.1 \\
\hline & & $0.0-25.0$ & & $0.0-82.1$ & & & & $0.0-40.0$ & & $0.0-82.1$ \\
\hline \multirow[t]{2}{*}{$\geq 6 \mathrm{~mm}$} & 13 & 14.8 & 5 & 30.0 & 7 & NA & 20 & 25.3 & 45 & 22.3 \\
\hline & & $0.0-33.3$ & & $14.3-42.9$ & & & & $0.0-80.8$ & & $0.0-80.8$ \\
\hline Total & 44 & & 70 & & 107 & & 90 & & 311 & \\
\hline
\end{tabular}


Table 4 Distribution of variable groups by periodontal status (PD and BOP): mean (range) or number (\%)

\begin{tabular}{|c|c|c|c|c|c|c|c|c|c|}
\hline \multirow{3}{*}{$\mathbf{N}$} & \multicolumn{4}{|l|}{ PD } & \multirow{3}{*}{$P^{\S}$} & \multicolumn{3}{|l|}{ BOP } & \multirow{3}{*}{$P^{\S}$} \\
\hline & $<4 \mathrm{~mm}$ & $4+5 \mathrm{~mm}$ & $\geq 6 \mathrm{~mm}$ & Total & & No & Yes & Total & \\
\hline & 166 & 101 & 44 & 311 & & 59 & 150 & 209 & \\
\hline \multicolumn{10}{|l|}{ Dental health care variables } \\
\hline No of teeth & $25.8(6-28)$ & $24.7(4-28)$ & $22.3(3-28)$ & $24.9(3-28)$ & 0.0001 & $24.6(13-28)$ & $26.4(4-28)$ & $25.5(4-28)$ & 0.05 \\
\hline No of teeth with caries & $0.10(0-4)$ & $0.21(0-4)$ & $0.41(0-6)$ & $0.18(0-6)$ & 0.01 & $0.27(0-4)$ & $0.23(0-6)$ & $0.24(0-6)$ & 0.64 \\
\hline No of teeth with restorations & $7.45(0-18)$ & $7.84(0-16)$ & $7.39(0-22)$ & $7.57(0-22)$ & 0.65 & $7.68(0-18)$ & $6.41(0-16)$ & $6.77(0-18)$ & 0.16 \\
\hline No of implants & $0.18(0-4)$ & $0.22(0-6)$ & $0.11(0-2)$ & $0.18(0-6)$ & 0.74 & $0.27(0-6)$ & $0.13(0-6)$ & $0.17(0-6)$ & 0.45 \\
\hline No of teeth with bridges & $0.47(0-7)$ & $1.11(0-7)$ & $1.50(0-8)$ & $0.82(0-8)$ & $<.0001$ & $0.56(0-7)$ & $0.85(0-8)$ & $0.77(0-8)$ & 0.26 \\
\hline No of teeth with crowns & $2.46(0-20)$ & $5.19(0-23)$ & $4.59(0-18)$ & $3.65(0-23)$ & $<.0001$ & $3.12(0-22)$ & $4.06(0-23)$ & $3.79(0-23)$ & 0.08 \\
\hline
\end{tabular}

\section{Lifestyle, anthropometric, health related and sociodemographic variables}

\begin{tabular}{|c|c|c|c|c|c|c|c|c|c|}
\hline BMI & $23.9(16.6-36.3)$ & $26.1(17.2-39.6)$ & $27.8(17.4-43.0)$ & $25.2(16.6-43.0)$ & $<.0001$ & $24.3(17.6-36.3)$ & $25.1(17.2-43.0)$ & $24.9(17.2-43.0)$ & 0.45 \\
\hline \multicolumn{10}{|l|}{ Diabetes } \\
\hline Yes & $5(3.0)$ & $10(9.9)$ & $4(9.1)$ & $19(6.1)$ & \multirow[t]{2}{*}{0.06} & $1(1.7)$ & $8(45.3)$ & $9(4.3)$ & \multirow[t]{2}{*}{0.24} \\
\hline No & $161(97.0)$ & $91(90.1)$ & $40(90.9)$ & $292(93.9)$ & & $58(98.3)$ & $142(94.7)$ & $200(95.7)$ & \\
\hline \multicolumn{10}{|l|}{ Physical activity } \\
\hline$<1500^{\&}$ & $52(31.3)$ & $30(29.7)$ & $12(27.3)$ & $94(30.2)$ & \multirow[t]{2}{*}{0.83} & $16(17.1)$ & $46(30.7)$ & $62(29.7)$ & \multirow[t]{2}{*}{0.61} \\
\hline$\geq 1500$ & $114(68.7)$ & $71(70.3)$ & $32(72.7)$ & $217(69.8)$ & & $43(72.9)$ & $104(69.3)$ & $147(70.3)$ & \\
\hline \multicolumn{10}{|l|}{ Sex } \\
\hline male & $61(36.8)$ & $36(35.6)$ & $23(52.3)$ & 120 (38.6) & \multirow[t]{2}{*}{0.14} & $19(50.0)$ & $48(42.9)$ & $67(44.7)$ & \multirow[t]{2}{*}{0.35} \\
\hline female & $105(63.2)$ & $65(64.4)$ & $21(47.7)$ & $191(61.4)$ & & $19(50.0)$ & $64(57.1)$ & $83(55.3)$ & \\
\hline Age & $41.0(21.0-76.0)$ & $52.1(20.0-77.0)$ & $54.0(26.0-69.0)$ & $46.4(20.0-77.0)$ & $<.0001$ & $42.9(21.0-68.0)$ & $45.5(20.0-70.0)$ & $44.8(20.0-70.0)$ & 0.25 \\
\hline \multicolumn{10}{|l|}{ Household income } \\
\hline$<2000 €$ & $53(31.9)$ & $36(35.6)$ & $14(31.8)$ & $103(33.1)$ & \multirow[t]{2}{*}{0.79} & $17(28.8)$ & $53(35.3)$ & $70(33.5)$ & \multirow[t]{2}{*}{0.37} \\
\hline$\geq 2000 €$ & $113(68.1)$ & $65(64.4)$ & $30(68.2)$ & $208(66.9)$ & & $42(71.2)$ & $97(64.7)$ & $139(66.5)$ & \\
\hline \multicolumn{10}{|l|}{ School education } \\
\hline$<13$ years & $70(42.2)$ & $65(64.4)$ & $35(79.6)$ & $170(54.7)$ & \multirow[t]{2}{*}{$<.0001$} & $25(42.4)$ & $81(54.0)$ & $106(50.7)$ & \multirow[t]{2}{*}{0.13} \\
\hline 13 years & $96(57.8)$ & $36(35.6)$ & $9(20.4)$ & $141(45.3)$ & & $34(57.6)$ & $69(46.0)$ & $103(49.3)$ & \\
\hline \multicolumn{10}{|l|}{ Smoking } \\
\hline Never & $98(59.0)$ & $60(59.4)$ & $16(36.4)$ & $174(55.9)$ & \multirow[t]{3}{*}{0.001} & $32(54.2)$ & $73(48.7)$ & $105(50.2)$ & \multirow[t]{3}{*}{0.82} \\
\hline Ex-smoker & $36(21.7)$ & $30(29.7)$ & $8(18.2)$ & $74(23.8)$ & & $9(15.3)$ & $38(25.3)$ & $47(22.5)$ & \\
\hline Current smoker & $32(19.3)$ & $11(10.9)$ & $20(45.4)$ & $63(20.3)$ & & $18(30.5)$ & $39(26.0)$ & $57(27.3)$ & \\
\hline \multicolumn{10}{|l|}{ Alcohol } \\
\hline$<2$ times/week & $101(60.8)$ & $65(64.4)$ & $26(59.1)$ & $192(61.7)$ & \multirow[t]{2}{*}{0.80} & $31(52.5)$ & $92(61.3)$ & $123(58.8)$ & \multirow[t]{2}{*}{0.25} \\
\hline$\geq 2$ times/week & 65 (39.2) & 36 (35.6) & $18(40.9)$ & 119 (38.3) & & $28(47.5)$ & $58(38.7)$ & $86(41.2)$ & \\
\hline \multicolumn{10}{|l|}{ lood parameters } \\
\hline Leukocytes & $6.2(2.9-22.4)$ & $6.4(3.4-12.4)$ & $7.0(4.1-11.5)$ & $6.4(2.9-22.4)$ & 0.04 & $6.1(3.1-10.5)$ & $6.6(2.9-22.4)$ & $6.4(2.9-22.4)$ & 0.08 \\
\hline $\mathrm{HbA1c}$ & $33.8(12.6-46.0)$ & $35.8(22.4-66.0)$ & $40.0(26.8-60.0)$ & $35.3(12.6-66.0)$ & $<.0001$ & $37.0(28.0-46.0)$ & $38.2(25.0-66.0)$ & $37.3(25.0-66.0)$ & 0.24 \\
\hline Erythrocytes & $4.5(3.4-5.8)$ & $4.5(3.8-5.5)$ & $4.6(3.9-5.2)$ & $4.5(3.4-5.8)$ & 0.89 & $4.5(3.4-5.4)$ & $4.5(3.8-5.6)$ & $4.5(3.4-5.6)$ & 0.42 \\
\hline $\begin{array}{l}\text { Mean corpuscular/cell } \\
\text { volume (MCV) }\end{array}$ & $87.1(70.0-96.3)$ & $87.7(74.0-96.7)$ & $88.8(81.0-99.9)$ & $87.5(70.0-99.9)$ & 0.04 & $87.1(76.8-94.7)$ & $87.5(70.0-99.9)$ & $87.4(70.0-99.9)$ & 0.27 \\
\hline
\end{tabular}

${ }^{\S}$ Kruskal-Wallis-Test.

\&MET (metabolic equivalent of task)/week.

periodontitis is again found to be high in the German population. This study showed that high BMI and smoking are significantly associated with increasing PD levels.

\section{(i) Dental parameters}

Dental plaque is a shared etiological factor for developing dental caries and periodontitis and it has been discussed that caries and periodontitis are antagonizing 
Table 5 Results of multivariable ordinal logistic regression on pocket depth (PD), $\mathbf{N}=\mathbf{3 1 1}$ and multivariable logistic regression on bleeding on probing (BOP), $N=209$ : Odds ratio (OR), confidence interval $(\mathrm{Cl})$ and $p$-values

\begin{tabular}{|c|c|c|c|c|c|c|}
\hline \multirow[b]{2}{*}{ Effect } & \multicolumn{3}{|l|}{ PD } & \multicolumn{3}{|l|}{ BOP } \\
\hline & OR & $95 \% \mathrm{Cl}$ & $\mathbf{p}$ & OR & $95 \% \mathrm{Cl}$ & $\mathbf{p}$ \\
\hline \multicolumn{7}{|l|}{ Lifestyle and anthropometric factors } \\
\hline BMI (increase by 5) & 1.66 & $1.25-2.21$ & 0.0004 & 1.21 & $0.81-1.81$ & 0.36 \\
\hline Alcohol (more or equal vs. less than 2 times per week) & 0.60 & $0.34-1.06$ & 0.08 & 0.61 & $0.29-1.28$ & 0.19 \\
\hline Physical activity (high vs. low) & 1.34 & $0.79-2.29$ & 0.28 & 0.90 & $0.44-1.86$ & 0.78 \\
\hline Smoking never & 1 & & & 1 & & \\
\hline Ex-smoker & 1.13 & $0.61-2.09$ & 0.69 & 1.94 & $0.79-4.80$ & 0.15 \\
\hline Current & 2.44 & $1.24-4.80$ & 0.01 & 1.03 & $0.46-2.29$ & 0.95 \\
\hline \multicolumn{7}{|l|}{ Socio-economic factors } \\
\hline Household income $\geq 2000 €$ vs $<2000 €$ & 0.86 & $0.51-1.46$ & 0.58 & 0.77 & $0.38-1.53$ & 0.45 \\
\hline School (13 years vs. <13 years) & 0.61 & $0.35-1.04$ & 0.07 & 0.74 & $0.32-1.70$ & 0.48 \\
\hline
\end{tabular}

Adjusted for age, sex and center.

[43]. In case of aggressive periodontitis where plaque is not a major etiological factor a lower prevalence of caries lesions can be found compared to patients with chronic periodontitis [44]. However, Kinane et al. [45] were not able to find any patterns of relationship between caries and periodontitis. A possible reason for the effect of caries in our study could be that only cavitated carious lesions were included (ICDAS $\geq 3$ ). This might represent a subpopulation of people that might neglect dental attendance or dental hygiene. Besides caries also the crowns and bridges showed a significant difference between the three PD groups. This might be as well contributed to the role of plaque and an insufficient ability of proper dental hygiene. In future analyses oral hygiene should be noted at least in a questionnaire.

\section{(ii) Lifestyle and anthropometric factors}

Smoking was positively associated with periodontitis in our study population. However, the use of smoking status in three categories (non-smoking, ex-smoking and current smoking) might have influenced the analyses. Ideally, smoking should be used in further analyses e.g. in amount of pack-years or at least amount of cigarettes smoked. Especially in cases of BOP it has been discussed in recent literature that people have less BOP with higher smoking rates [46]. However, we have not considered this issue further and could not find any associations for BOP

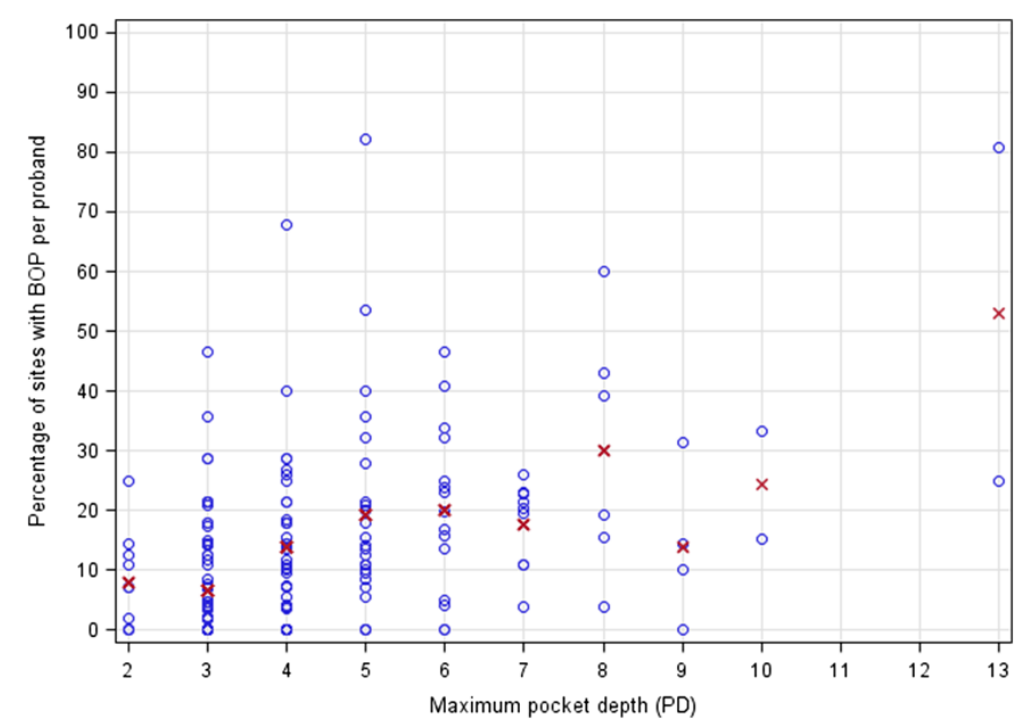

Figure 1 Distribution of maximum pocket depth (PD) with percentages of bleeding on probing (BOP) sites per person in correlation to sites of BOP per patient ${ }^{*}{ }^{*}$ dots represent individual observations, red $\times$ represent mean percentage per pocket depth value. 
with smoking in our analysis. Limitations due to the number of persons for BOP analysis are obvious.

Our findings on BMI are in concordance with already published papers [47]. There was a significant association between BMI and periodontitis and also an increase of BMI with higher ages. Benguigui showed that plaque index and deeper pockets are influenced by BMI level [48]. In particular, the age-specific associations showed the same tendency as in other studies in which a higher BMI was expected with increasing age. However, correlations between age and BMI on the lifestyle could still be present. Issues of nutrition and food intake, less oral hygiene could also have a direct association or indirect relationship with PD, however, we could not test for those factors any further.

\section{(iii) Blood parameters}

Parameters like leukocytes, HbA1c, erythrocytes and mean corpuscular/cell volume (MCV) have been proposed to have an effect on PD and BOP [49]. Patients with periodontitis have a large chronically inflamed wound area, which enable periodontal pathogens or bacterial endproducts to get into the blood stream. This can cause systemic changes in blood homeostasis which could favor other chronic systemic diseases.

However, in case of periodontal diseases blood parameters have to be treated with caution. Whereas other variables could have a direct causal link to periodontitis, higher values of laboratory parameters like leukocytes and HbA1c might be due to inflammations from other parts of the body. Hence, interpretation of results based on laboratory parameters is limited. We have therefore not considered laboratory variables in regression analyses. However, Kruskal-Wallis-Test showed only for HbA1c a significant difference between 3 groups with different severity of periodontitis in our study. None of the other laboratory variables were significant when tested for BOP or PD.

Leukocyte counts showed a significant difference within the three periodontitis groups in our study. There are hints in literature supporting the findings of an association of periodontitis with elevated leukocytes but up to date a clear correlation could not be found [49]. A recent study based on three different groups of periodontitis showed similar results on leukocytes as compared to our study population [50].

Signs of anaemia can be associated with chronic inflammatory conditions due to a cytokine mediated depletion of erythropoin [51]. Lainson et al. was one of the first who raised such a question in periodontitis [52]. Erythrocyte parameters like haematocrit, mean corpuscular haemoglobin/volume, haemoglobin and erythrocyte counts were significantly different in patients with aggressive periodontitis [53]. In our study population, however, this can only be partly confirmed by an increase in MCV values within the three groups with different severity of periodontitis.

However, physical activity failed to show any statistical significance and an increase in HbA1c levels in our mostly non diabetic population could be noted. Nevertheless this represents a well known phenomenon [54] thus increased HbA1c values might have an impact on the immune reaction of the periodontium.

All centers followed the standard operating procedures (SOPs) and used standardized questionnaires, which minimizes differences between the centers. Nevertheless differences of trainers- (dentists) and trainees- (study nurses) and inter center methods could vary slightly due to missing calibration prior to the feasibility study. In the present study, differences between the study centers and examiners might be present, although the attempt was made to keep the conditions constant across the centers.

In this study, only a half-mouth assessment for periodontal status was conducted, but the allocation of each side was randomized and was set at two sites per tooth. As a consequence, the findings could not be extended to consider the entire mouth. However, basic dental parameters were investigated full mouth and had to be slightly adapted for Berlin (see Methods section). Some studies performed a half mouth examination, whereas others had full mouth [55]. Studies have shown that in using half-mouth examination there might be some underestimation of disease prevalence [56]. In a recent systematic review half mouth periodontal chart showed a relatively high sensitivity if performed on six sites per tooth [57]. Both methods are convenient and in accordance with clinical methods in the literature, but highly dependent on resources and time constraints [58]. Due to a limited time period, the complete investigation was shortened to some important parts.

We have considered PD and BOP by two regression models independently. In general, there is a correlational link between PD and BOP which we could at least show as the percentages of mean BOP sites increase with deeper pockets. However, no significant differences in BOP were found as they have been associated with the various variables and especially the laboratory parameters $[49,53]$. This could have been influenced by the small number of individuals with BOP in this study.

In further research on the prevalence of periodontitis not only PD should be taken into account. Attachment level (AL) is an important factor to define the magnitude and the severity [59] of the disease accurately. Therefore, both parameters are very important in combination and should be considered in further studies/analyses. On the other hand, inter examiner data showed that it was difficult to train study nurses in measuring reliable outcomes 
in AL. In case of measuring attachment level no reliable data were obtained from study nurses. Because of this it was decided to use maximal pocket depths as a marker for periodontal inflammation and to intensify the clinical training protocol for study nurses. As AL was not generally measured in all centers (only HD) it could not be compared, so only the PD was analyzed commonly.

For future research questions about oral hygiene status have to be included into the study questionnaire because it is likely that there might be confounding effects for tested variables. Ideally in further studies, smoking should be assessed as pack-years, or at least number of cigarettes smoked per day. Socioeconomic variables should be addressed precisely as they often have been discussed in literature to have an effect on periodontal diseases.

\section{Conclusions}

Increased BMI and smoking are associated with periodontitis risk. Dental variables found to be linked with pocket depth are caries lesions, number of bridges and crowns. Further associations of periodontitis with immunological parameters like leukocytes, HbA1c, MCV were found, however, a causal relation cannot be deduced from this study.

\section{Competing interests}

This work was supported by the German Ministry of Education and Research (BMBF). The authors declare that they have no competing interests.

\section{Authors' contributions}

$\mathrm{HZ}$ procured the data, drafted the manuscript and performed the analyses. $\mathrm{DH}$ drafted the manuscript and contributed to the data collection (acquisition of data). KD contributed to the conception of the study and the design and critical revision of the manuscript. NES contributed to the data collection (acquisition of data). JF obtained funding, contributed to data collection (acquisition of data) and critical revision of the manuscript. KHG ensured the financial funding and running of the study, enabled data collection and critically reviewed the manuscript. JK contributed to the conception of the study and the design, to data collection (acquisition of data) and critical revision of the manuscript. $J L$ ensured the financial funding and running of the study, enabled data collection and critically reviewed the manuscript. CM ensured the financial funding and running of the study, enabled data collection and critically reviewed the manuscript. NP contributed to data collection (acquisition of data), running of the study, contributed to securing funding for the study and to the examination, and to administrative, technical, or material support, contributed to supervising the study and the examinations, interpretation of data, and to critical revisions of the manuscript. TP contributed to data collection (acquisition of data) and running of the study, contributed to securing funding for the study and to the examination, and to administrative, technical, or material support, contributed to supervising the study and the examinations, interpretation of data, and to critical revisions of the manuscript. SS contributed to the critical revision of the manuscript. MS contributed to the data collection and critical revision of the manuscript. AS contributed to data collection (acquisition of data) and running of the study, contributed to supervising the study and the examinations, interpretation of data, and to critical revisions of the manuscript. TSK contributed to the conception of the study and the design, and critically reviewed the manuscript. $\mathrm{HB}$ procured the data, drafted the manuscript, contributed to the analyses and the calculations. All authors contributed in writing the manuscript and read and approved the final version.

\section{Acknowledgments}

The authors would like to thank all participants in this study. This project was conducted in the context of the pretest studies of the German National Cohort (www.nationale-kohorte.de). These were funded by the Federal Ministry of Education and Research (BMBF), Förderkennzeichen 01ER1001A-I and supported by the Helmholtz Association as well as by the participating universities and Institutes of the Leibniz Association. The study was approved by all local ethics committees of the participating centers. We acknowledge financial support by Deutsche Forschungsgemeinschaft and Ruprecht-KarlsUniversität Heidelberg within the funding program Open Access Publishing.

\section{Author details}

${ }^{1}$ Institute of Public Health, University of Heidelberg, Im Neuenheimer Feld 324, 69120 Heidelberg, Germany. ${ }^{2}$ Department of Conservative Dentistry, Section of Periodontology, University of Heidelberg, Im Neuenheimer Feld 400, 69120 Heidelberg, Germany. ${ }^{3}$ Policlinic of Periodontology, University-Hospital of Münster, Münster, Germany. ${ }^{4}$ Department of Orthodontics, University of Heidelberg, Im Neuenheimer Feld 400, 69120 Heidelberg, Germany. ${ }^{5}$ Division of Cancer Epidemiology, German Cancer Research Center, Im Neuenheimer Feld, 581, 69120 Heidelberg, Germany. ${ }^{6}$ Institute for Social Medicine, Epidemiology and Health Economics, Charité-Universitätsmedizin Berlin, Luisenstr. 57, 10117 Berlin, Germany. ${ }^{7}$ Department of Conservative Dentistry and Periodontology, Ludwig-Maximilians-University of Munich, Goethestraße 70, 80336 München, Germany. ${ }^{8}$ Helmholtz Zentrum München, German Research Center for Environmental Health, Institute of Epidemiology II, Neuherberg, Germany. ${ }^{9}$ Department of Periodontology and Synoptic Dentistry, Charité - University Medicine Berlin, Berlin, Germany. ${ }^{10}$ Molecular Epidemiology Research Group, Max Delbrück Center for Molecular Medicine (MDC) Berlin-Buch, Robert-Rössle-Strasse 10, 13125 Berlin, Germany. ${ }^{11}$ Poliklinik für zahnärztliche Prothetik und Medizinische Werkstoffkunde Zentrum für Zahn, Mund- und Kieferheilkunde Universitätsmedizin Greifswald, Greifswald, Germany.

${ }^{12}$ Department of Prosthodontics, Im Neuenheimer Feld 400, 69120 Heidelberg, Germany. ${ }^{13}$ Institute of Medical Biometry and Epidemiology, University Medical Center Hamburg-Eppendorf, Martinistr. 52, 20246, Hamburg, Germany.

Received: 23 July 2014 Accepted: 3 January 2015 Published: 21 January 2015

\section{References}

1. Schaudinn C, Gorur A, Keller D, Sedghizadeh PP, Costerton JW. Periodontitis: an archetypical biofilm diseas. J Am Dent Assoc. 2009;140:978-86.

2. Socransky SS, Haffajee AD. The bacterial etiology of destructive periodontal disease: current concepts. J Periodontol. 1992;63:322-31.

3. Page RC, Kornman KS. The pathogenesis of human periodontitis: an introduction. Periodontol. 1997;14:9-11.

4. Calsina G, Ramón J-M, Echeverría J-J. Effects of smoking on periodontal tissues. J Clin Periodontol. 2002;29:771-6.

5. Johnson GK, Slach NA. Impact of tobacco use on periodontal status. J Dent Educ. 2001;65:313-21.

6. Salvi GE, Carollo-Bittel B, Lang NP. Effects of diabetes mellitus on periodontal and peri-implant conditions: update on associations and risks. J Clin Periodontol. 2008:35:398-409.

7. Emrich LJ, Shlossman M, Genco RJ. Periodontal-Disease in Non-InsulinDependent Diabetes-Mellitus. J Periodontol. 1991;62:123-31.

8. Hodge PJ, Robertson D, Paterson K, Smith GL, Creanor S, Sherriff A. Periodontitis in non-smoking type 1 diabetic adults: a cross-sectional study. J Clin Periodontol. 2012;39:20-9.

9. Schaefer AS, Richter GM, Groessner-Schreiber B, Noack B, Nothnagel M, El Mokhtari NE, et al. Identification of a shared genetic susceptibility locus for coronary heart disease and periodontitis. PLoS Genet. 2009;5:e1000378.

10. Schaefer AS, Richter GM, Nothnagel M, Laine ML, Ruhling A, Schafer C, et al. A 3' UTR transition within DEFB1 is associated with chronic and aggressive periodontitis. Genes Immun. 2010;11:45-54.

11. Schaefer AS, Richter GM, Nothnagel M, Manke T, Dommisch H, Jacobs G, et al. A genome-wide association study identifies GLT6D1 as a susceptibility locus for periodontitis. Hum Mol Genet. 2010;19:553-62.

12. Cobb CM, Williams KB, Gerkovitch MM. Is the prevalence of periodontitis in the USA in decline? Periodontol. 2009;50:13-24. 
13. Locker D, Slade GD, Murray H. Epidemiology of periodontal disease among older adults: a review. Periodontol. 1998;16:16-33.

14. Genco RJ. Current view of risk factors for periodontal diseases. J Periodontol. 1996;67:1041-9.

15. Timmerman MF, der Weijden GAV. Risk factors for periodontitis. Int J Dent Hyg. 2006;4:2-7.

16. Heitz-Mayfield LJ. Disease progression: identification of high-risk groups and individuals for periodontitis. J Clin Periodontol. 2005;32:196-209.

17. Pistorius A, Krahwinkel T, Willershausen B, Boekstegen C. Relationship between stress factors and periodontal disease. Eur J Med Res. 2002; 7:393-8.

18. Gorelick PB. Stroke prevention therapy beyond antithrombotics: unifying mechanisms in ischemic stroke pathogenesis and implications for therapy. Stroke. 2002;33:862-75.

19. Grau AJ, Becher H, Ziegler CM, Lichy C, Buggle F, Kaiser C, et al. Periodontal disease as a risk factor for ischemic stroke. Stroke. 2004;35:496-501.

20. Kim H-D, Sim S-J, Moon J-Y, Hong Y-C, Han D-H. Association between periodontitis and hemorrhagic stroke among Koreans: a case-control study. J Periodontol. 2010;81:658-65.

21. Bahekar AA, Singh S, Saha S, Molnar J, Arora R. The prevalence and incidence of coronary heart disease is significantly increased in periodontitis: a meta-analysis. Am Heart J. 2007;154:830-7.

22. Persson GR, Persson RE. Cardiovascular disease and periodontitis: an update on the associations and risk. J Clin Periodontol. 2008;35:362-79.

23. Andriankaja OM, Genco RJ, Dorn J, Dmochowski J, Hovey K, Falkner KL, et al. Periodontal disease and risk of myocardial infarction: the role of gender and smoking. Eur J Epidemiol. 2007;22:699-705.

24. Cueto A, Mesa F, Bravo M, Ocaña-Riola R. Periodontitis as risk factor for acute myocardial infarction. A case control study of Spanish adults. J Periodontal Res. 2005;40:36-42.

25. Georgiou T, Marshall R, Bartold MP. Prevalence of systemic diseases in Brisbane general and periodontal practice patients. Aust Dent J. 2004:49:177-84.

26. Niedzielska I, Janic T, Cierpka S, Swietochowska E. The effect of chronic periodontitis on the development of atherosclerosis: review of the literature. Med Sci Monit. 2008;14:RA103-6.

27. Bourgeois $D$, Bouchard $P$, Mattout C. Epidemiology of periodontal status in dentate adults in France, 2002-2003. J Periodontal Res. 2007;42:219-27.

28. Gera I. Periodontal treatment needs in Central and Eastern Europe. Fogorv Sz. 2004:97:179-89

29. Holtfreter B, Kocher T, Hoffmann T, Desvarieux M, Micheelis W. Prevalence of periodontal disease and treatment demands based on a German dental survey (DMS IV). J Clin Periodontol. 2010;37:211-9.

30. Petersen PE, Bourgeois D, Ogawa H, Estupinan-Day S, Ndiaye C. The global burden of oral diseases and risks to oral health. Bull World Health Organ. 2005;83:661-9.

31. Micheelis W. Oral health in Germany: an oral epidemiological outline. Bundesgesundheitsblatt Gesundheitsforschung Gesundheitsschutz. 2011;54:1022-6.

32. Demmer RT, Papapanou PN. Epidemiologic patterns of chronic and aggressive periodontitis. Periodontol. 2010;53:28-44.

33. Gatke D, Holtfreter B, Biffar R, Kocher T. Five-year change of periodontal diseases in the Study of Health in Pomerania (SHIP). J Clin Periodontol. 2012;39:357-67.

34. Struch F, Dau M, Schwahn C, Biffar R, Kocher T, Meisel P. Interleukin-1 gene polymorphism, diabetes, and periodontitis: results from the Study of Health in Pomerania (SHIP). J Periodontol. 2008;79:501-7.

35. Demmer RT, Desvarieux M, Holtfreter B, Jacobs Jr DR, Wallaschofski $H_{\text {, }}$ Nauck M, et al. Periodontal status and A1C change: longitudinal results from the study of health in Pomerania (SHIP). Diabetes Care. 2010;33:1037-43.

36. Holtfreter B, Schwahn C, Biffar R, Kocher T. Epidemiology of periodontal diseases in the Study of Health in Pomerania. J Clin Periodontol. 2009;36:114-23.

37. Wichmann HE, Kaaks R, Hoffmann W, Jockel KH, Greiser KH, Linseisen J. The German national cohort. Bundesgesundheitsblatt Gesundheitsforschung Gesundheitsschutz. 2012:55:781-7.

38. German National Cohort (GNC) Consortium. The German national cohort: aims, study design and organization. Eur J Epidemiol. 2014;29:371-82.

39. Cutress TW, Ainamo J, Sardo-Infirri J. The community periodontal index of treatment needs (CPITN) procedure for population groups and individuals. Int Dent J. 1987;37:222-33.
40. Lang NP, Adler R, Joss A, Nyman S. Absence of bleeding on probing. An indicator of periodontal stability. J Clin Periodontol. 1990;17:714-21.

41. Lang NP, Joss A, Orsanic T, Gusberti FA, Siegrist BE. Bleeding on probing. A predictor for the progression of periodontal disease? J Clin Periodontol. 1986;13:590-6.

42. Ismail Al, Sohn W, Tellez M, Amaya A, Sen A, Hasson H, et al. The International Caries Detection and Assessment System (ICDAS): an integrated system for measuring dental caries. Community Dent Oral Epidemiol. 2007;35:170-8.

43. Li DY, Guo JJ, Zhao JJ, Ge SY, Wang ZH, Ye J. Analysis of pathogenic relations between dental caries and periodontitis. Shanghai kou qiang yi xue $=$ Shanghai journal of stomatology. 2002;11:289-90.

44. Al Omari MA, Al Habashneh R, Taanni DQ. Dental caries experience in patients with aggressive periodontitis compared to those with chronic periodontitis. Quintessence Int. 2008;39:847-51.

45. Kinane DF, Jenkins WM, Adonogianaki E, Murray GD. Cross-sectional assessment of caries and periodontitis risk within the same subject. Community Dent Oral Epidemiol. 1991;19:78-81.

46. Pitiphat W, Merchant AT, Rimm EB, Joshipura KJ. Alcohol consumption increases periodontitis risk. J Dent Res. 2003;82:509-13.

47. Dietrich T, Bernimoulin JP, Glynn RJ. The effect of cigarette smoking on gingival bleeding. J Periodontol. 2004;75:16-22.

48. Benguigui C, Bongard V, Ruidavets JB, Sixou M, Chamontin B, Ferrieres J, et al. Evaluation of oral health related to body mass index. Oral Dis. 2012;18:748-55.

49. Loos BG. Systemic markers of inflammation in periodontitis. J Periodontol. 2005;76:2106-15.

50. Kalburgi V, Sravya L, Warad S, Vijayalaxmi K, Sejal P, Hazeil D. Role of systemic markers in periodontal diseases: a possible inflammatory burden and risk factor for cardiovascular diseases? Ann Med Health Sci Res. 2014:4:388-92.

51. Nemeth E, Rivera S, Gabayan V, Keller C, Taudorf S, Pedersen BK, et al. IL-6 mediates hypoferremia of inflammation by inducing the synthesis of the iron regulatory hormone hepcidin. J Clin Invest. 2004;113:1271-6.

52. Lainson PA, Brady PP, Fraleigh CM. Anemia, a systemic cause of periodontal disease? J Periodontol. 1968:39:35-8.

53. Anand PS, Sagar DK, Ashok S, Kamath KP. Association of aggressive periodontitis with reduced erythrocyte counts and reduced hemoglobin levels. J Periodontal Res. 2014;49:719-28.

54. Hayashida H, Kawasaki K, Yoshimura A, Kitamura M, Furugen R, Nakazato M, et al. Relationship between periodontal status and $\mathrm{HbAlC}$ in nondiabetics. J Public Health Dent. 2009:69:204-6.

55. Holtfreter B, Demmer RT, Bernhardt O, Papapanou PN, Schwahn C, Kocher T, et al. A comparison of periodontal status in the two regional, populationbased studies of SHIP and INVEST. J Clin Periodontol. 2012:39:1115-24.

56. Albandar JM. Underestimation of periodontitis in NHANES surveys. J Periodontol. 2011;82:337-41.

57. Tran DT, Gay I, Du XL, Fu Y, Bebermeyer RD, Neumann AS, et al. Assessing periodontitis in populations: a systematic review of the validity of partialmouth examination protocols. J Clin Periodontol. 2013;40:1064-71.

58. Thomson WM, Williams SM. Partial- or full-mouth approaches to assessing the prevalence of and risk factors for periodontal disease in young adults. J Periodontol. 2002;73:1010-4.

59. Armitage GC. Development of a classification system for periodontal diseases and conditions. Northwest Dent. 2000;79:31-5.

doi:10.1186/1472-6831-15-7

Cite this article as: Zimmermann et al:: Pocket depth and bleeding on probing and their associations with dental, lifestyle, socioeconomic and blood variables: a cross-sectional, multicenter feasibility study of the German National Cohort. BMC Oral Health 2015 15:7. 